\title{
TINJAUAN KECEPATAN KENDARAAN PADA WILAYAH ZoSS DI JALAN LINTAS TIMUR PROVINSI RIAU
}

\author{
Fitridawati Soehardi \\ Program Studi Teknik Sipil Universitas Lancang Kuning \\ Jalan Yos Sudarso Km. 8 Rumbai Pekanbaru \\ E-mail : fitridawati@unilak.ac.id \\ Lusi Dwi Putri \\ Program Studi Teknik Sipil Universitas Lancang Kuning \\ Jalan Yos Sudarso Km. 8 Rumbai Pekanbaru \\ E-mail : lusidwiputri@unilak.ac.id \\ Alfian Saleh \\ Program Studi Teknik Sipil Universitas Lancang Kuning \\ Jalan Yos Sudarso Km. 8 Rumbai Pekanbaru \\ E-mail : alfiansaleh@unilak.ac.id
}

\begin{abstract}
Abstrak
Zona Selamat Sekolah (ZoSS) adalah lokasi atau wilayah di ruas jalan tertentu yang merupakan zona kecepatan berbasis waktu untuk mengatur kecepatan kendaraan di lingkungan sekolah. Batas kecepatan izin maksimum memasuki ZoSS khususnya di jalan lintas Timur adalah $25 \mathrm{~km} / \mathrm{jam}$ dan secara garis besar batas kecepatan izin kendaraan yang melewati ZoSS di Indonesia umumnya adalah $20-30 \mathrm{~km} / \mathrm{jam}$. Secara garis besar kecepatan kendaraan yang melalui lokasi ZoSS lebih tinggi dari kecepatan izin. Untuk memastikan kecepatan rata-rata kendaraan dan menentukan tingkat pelanggaran kendaraan yang melintasi wilayah ZoSS maka diperlukan data primer yang mana sampel diambil secara acak berdasarkan survey lapangan selama 3 (tiga) hari pada lokasi sekolah yang memiliki fasilitas ZoSS, yaitu SDN 002 Kiyap Jaya, SDN 004 Lubuk Ogong, SDN 012 Pangkalan Baru. Sebagai pembandingnya adalah sekolah yang tidak memiliki fasilitas ZoSS yaitu sekolah SDN 007Simpang Beringin, SDN 001 Sei Kijang, dan TK Karya Bunda. Data diambil pada kondisi jam sibuk yaitu pukul 06.0008.00 dan pada pukul 11.00-13.00 WIB. Data yang didapat adalah jarak tempuh dan waktu tempuh kendaraan. Kedua data tersebut dapat menghasilkan nilai kecepatan baik itu kecepatan tiap kendaraan maupun kecepatan rata-rata kendaraan yang melewati wilayah ZoSS. Hasil dari penelitian, kecepatan kendaraan yang melewati wilayah ZoSS tidak sesuai dengan kecepatan izin yaitu $34 \mathrm{~km} / \mathrm{jam}$ sedangkan kecepatan rata-rata pada wilayah yang tidak memilki fasilitas ZoSS adalah $36 \mathrm{~km} / \mathrm{jam}$. Hal ini menunjukkan bahwa kendaraan yang melewati ZoSS ini tidak mengikuti peraturan batas maksimum wilayah ZoSS dan dapat berpotesi membahayakan siswa-siswa Sekolah Dasar pengguna jalan.
\end{abstract}

Kata Kunci : Jarak Tempuh, Kecepatan, Waktu Tempuh, Zona Selamat Sekolah (ZoSS) 


\begin{abstract}
The School Safe Zone (ZoSS) is a location or area on a particular road segment that is a time-based velocity zone to regulate vehicle speed in a school setting. Maximum permission speed limit entering ZoSS especially on the eastern road is $25 \mathrm{~km} / \mathrm{h}$ and in general the speed limit of vehicle permits passing through ZoSS in Indonesia generally is 20-30 km/h. Broadly speaking, vehicle speed through ZoSS location is higher than permission speed. To ensure the average speed of the vehicle and to determine the level of vehicle violations across the ZoSS region, primary data is needed where samples are drawn at random based on a 3 (three) day field survey at a school site with ZoSS facilities, SDN 002 Kiyap Jaya, SDN 004 Lubuk Ogong, SDN 012 Pangkalan Baru. As a comparison, schools that do not have ZoSS facilities are SDN 007 Simpang Beringin, SDN 001 Sei Kijang, and TK Karya Bunda. The data is taken at the rush hour condition at 06.00-08.00 and at 11.00-13.00 WIB. The data obtained is the distance and travel time of the vehicle. Both data can produce the speed value either the speed of each vehicle or the average speed of vehicles passing through ZoSS region. The results of the study, the speed of vehicles passing through the ZoSS region does not match the permited speed of $34 \mathrm{~km} / \mathrm{h}$ while the average speed in the area that does not have ZoSS facility is $36 \mathrm{~km} / \mathrm{h}$. This indicates that vehicles passing through this ZoSS do not follow ZoSS maximum area rules and can potentially harm students of Primary School road users.
\end{abstract}

Keywords : Distance, Speed, Competition, School Safe Zone (ZoSS)

\section{A. PENDAHULUAN}

Jalan Lintas Timur merupakan jalan yang menghubungkan Kota Pekanbaru dengan Kabupaten Siak dan Pelalawan, jalur ini merupakan jalur yang banyak dilalui kendaraan terutama mobil besar bermuatan berat dengan kecepatan yang tinggi. Hal ini dapat disebabkan dari mobilitas kendaraan dari dua perusahaan besar yang ada di daerah tersebut. Hampir sepanjang jalan lintas timur banyak terdapat sekolah yang berada di tepi jalan raya. Kondisi ini sangat membahayakan bagi para pengguna jalan terutama anak sekolah khususnya siswa SD (Sekolah Dasar) masih rentan dalam berlalu lintas seperti ketika menyeberang jalan.

Menurut data lakalantas dari Polresta Kota Pekanbaru, Kabupaten Pelalawan dan Kabupaten Siak tahun 2016 ini tidak terlalu signifikan dari tahun sebelumnya bahkan ada yang mengalami penurunan. Walaupun demikian, kita perlu antisipasi kondisi tersebut sebelum terjadi korban, mengingat objek penelitian ini adalah TK dan SD yang hampir seluruhnya dilakukan oleh anak-anak yang belum paham akan etika berlalu lintas yang baik dan benar khususnya pada saat jam masuk sekolah dan saat pulang sekolah. Tidak semua sekolah memiliki fasilitas ZoSS walaupun dari kondisi visual seharusnya layak mendapatkan ZoSS. Bahkan untuk beberapa sekolah yang memiliki fasilitas ZoSS kondisi terkini seperti tidak terawat misalnya warna jalan depan sekolah (biasanya berwarna merah) sudah tidak jelas lagi warnanya.

Pelaksanaan ZoSS merupakan salah satu bentuk manajemen lalulintas dalam rangka pemenuhan rasa aman dalam menyeberang jalan bagi pejalan kaki. Menurut Departemen Perhubungan Direktur Jenderal Perhubungan Darat (2006) "Zona 
Selamat Sekolah (ZoSS)" adalah lokasi di ruas jalan tertentu yang merupakan zona kecepatan berbasis waktu untuk mengatur kecepatan di lingkungan sekolah". Ini juga dijelaskan oleh Kementerian Perhubungan Direktorat Jenderal Perhubungan Darat (2014) "ZoSS adalah pengendalian kegiatan lalulintas melalui pengaturan kecepatan dengan penempatan marka dan rambu pada ruas jalan di lingkungan sekolah yang bertujuan untuk mencegah terjadi kecelakaan sebagai upaya menjamin keselamatan di sekolah".

\section{B. TINJAUAN PUSTAKA}

\section{Zona Selamat Sekolah (ZoSS)}

Zona Selamat Sekolah (ZoSS) adalah suatu zona untuk ruas jalan tertentu pada lingkungan sekolah dengan kecepatan yang berbasis waktu. Melalui rekayasa lalu lintas maka zona ini dilengkapi dengan fasilitas pendukung yang dapat mengatur kecepatan kendaraan. Pada Zona Selamat Sekolah (ZoSS) diharapkan lalu lintas yang aman,nyaman, mudah dan ekonomis. Fasilitas ZoSS dipasang pada sekolah yang berada pada jalan arteri dan kolektor. Pemasangan ZoSS pada jalan nasional yang merupakan jalan arteri atau kolektor primer 1 (KP 1) diperuntukkan khusus sekolah-sekolah yang sudah terbangun di tepi jalan nasional dan tidak ada alternatif pemindahan jalan masuk sekolah. Pada ZoSS fasilitas keselamatan jalan yang diperlukan adalah zebra cross, ramburambu peringatan, petunjuk lokasi penyeberangan dan rambu-rambu banyak anak-anak.

\section{Kecepatan Zona Selamat Sekolah (ZoSS)}

Untuk batas izin kecepatan di lokasi ZoSS yaitu $20 \mathrm{~km} / \mathrm{jam}, 25$ $\mathrm{km} / \mathrm{jam}$, dan $30 \mathrm{~km} / \mathrm{jam}$, penetapan dilakukan dengan survey terkait yaitu:

a. Perilaku pengguna jalan, meliputi perilaku pejalan kaki pada saat menyeberang jalan dan perilaku pejalan kaki menyusuri jalan.

b. Kondisi lalulintas, meliputi inventarisasi jalan, volume lalulintas, pejalan kaki, dan kecepatan kendaraan

Syarat adanya ZoSS adalah tidak tersedianya jembatan penyeberangan orang, sekolah yang mempunyai akses langsung ke jalan yang memiliki siswa diatas 50 siswa. Menurut Kementerian Perhubungan Direktorat Jenderal Perhubungan Darat (2014), berdasarkan kriteria letak sekolah, ZoSS dapat diklasifikasikan berdasarkan ZoSS tunggal dan jamak. ZoSS tunggal dan jamak terdiri dari 4 tipe ruas jalan yaitu tipe jalan 2/2 UD (dua lajur, dua arah tidak terbagi), tipe jalan 4/2 UD (empat lajur, dua jalur tidak terbagi), tipe jalan 2/2 D (dua lajur, dua arah terbagi), tipe jalan 4/2 D (empat lajur, dua jalur terbagi).

a. ZoSS tunggal

Merupakan ZoSS yang ditetapkan untuk 1 (satu) sekolah di suatu lokasi. Bentuk dan ukuran ZoSS tunggal terdiri dari 4 tipe ruas jalan yaitu ruas jalan tipe $2 / 2 \mathrm{UD}, 4 / 2 \mathrm{UD}$, 2/2 D, dan 4/2 D.

b. ZoSS jamak

Merupakan ZoSS yang ditetapkan untuk 2 (dua) sekolah atau lebih yang lokasinya saling berdekatan. ZoSS jamak dipasang dengan ketentuan zebra cross dan jarak terluar ZoSS. Zebra cross dipasang di setiap pintu atau akses masuk sekolah dan jarak terluar ZoSS diukur dari sekolah yang paling terluar. Jarak antara akses pintu masuk sekolah dengan sekolah lainnya $\geq 50$ meter, jika $<50$ 
meter, maka zebra cross digabung menjadi satu.

\section{Fasilitas Pelengkap Zona Selamat Sekolah (ZoSS)}

Fasilitas perlengkapan jalan pada wilayah ZoSS terdiri dari 3 (tiga) bagian yaitu :

a. Marka jalan

Menurut Warpani (2002), marka jalan adalah tanda berupa garis, gambar, anak panah, dan lambang pada permukaan jalan yang berfungsi mengarahkan arus lalulintas dan membatasi daerah kepentingan lalulintas. Marka jalan adalah mengandung pesan perintah, peringatan, petunjuk maupun larangan yang terdiri dari 3 (tiga) warna yaitu :

1) Marka berwarna putih, menyatakan bahwa pengguna jalan wajib mengikuti perintah atau larangan sesuai dengan bentuknya. Marka berwarna putih terdiri dari garis putih tunggal utuh, garis putih tunggal putusputus, garis putih ganda, garis putih utuh dan putih putus-putus dan garis putih penunjuk lajur.

2) Marka berwarna kuning, menyatakan bahwa pengguna jalan dilarang berhenti pada area tersebut.

3) Marka berwarna merah, marka jalan berwarna merah menyatakan keperluan atau tanda khusus.

\section{b. Rambu lalulintas}

Rambu lalulintas adalah bagian perlengkapan jalan yang berupa lambang, huruf, angka, kalimat, dan/atau perpaduan yang berfungsi sebagai peringatan, larangan, perintah atau petunjuk bagi pengguna jalan (Kemenhub, 2014). Jenis rambu terdiri atas 4 (empat) bagian yaitu :

1) Rambu peringatan, menunjukkan kemungkinan adaya bahaya dijalan yang akan dilalui. Rambu peringatan berbentuk belah ketupat, berwarna dasar kuning dengan lambang atau tulisan berwarna hitam.

2) Rambu larangan yaitu bentuk pengaturan berisi laranganlarangan yang tidak boleh dilakukan oleh pengguna jalan. Rambu larangan berbentuk lingkaran dengan warna dasar putih dan lambang atau tulisan berwarna hitam atau merah. Rambu larangan khusus berbentuk segi delapan sama sisi.

3) Rambu petunjuk yaitu memberikan petunjuk mengenai jurusan, keadaan jalan, situasi, kota berikutnya, keberadaan fasilitas, dan lain-lain. Rambu petunjuk berbentuk persegi panjang

4) Rambu perintah yaitu berbentuk pengaturan yang jelas dan tegas tanpa ada interpretasi lain yang wajib dilaksanakan oleh pengguna jalan. Rambu perintah berbentuk bulat, warna dasar biru dengan lambang atau tulisan berwarna putih serta merah untuk garis serong sebagai batas akhir perintah.

c. Alat pengaman pemakai jalan

Alat pengaman pemakai jalan yaitu berupa pita penggaduh. Pita penggaduh adalah kelengkapan tambahan pada jalan yang berfungsi untuk membuat pengemudi lebih 
meningkatkan kewaspadaan. Pita penggaduh dapat berupa suatu marka jalan atau bahan lain yang dipasang melintang jalur lalulintas dengan ketebalan maksimum $4 \mathrm{~cm}$. Sedangkan pita penggaduh untuk di Zona Selamat Sekolah dipasang dengan jarak 50 meter dari garis terluar ZoSS.

Pada volume lalulintas yang sangat rendah atau kosong dengan jalan yang sangat baik, maka pengendara dapat menjalankan kendaraannya sesuai dengan keinginannya dalam batas yang dirasakan aman, tanpa merasa dipengaruhi oleh keberadaan kendaraan lainnya. Pada kondisi ini dapat dikatakan bahwa lalulintas di jalan tersebut dikatakan arus bebas, dan kecepatan pada kondisi ini disebut kecepatan pada arus bebas. Namun apabila kondisi jalan dalam keadaan padat, banyak sekali faktor pejalan kaki yang menyeberang jalan, yang mempengaruhi jalan tersebut sehingga menimbulkan konflik. Hal yang mempengaruhi jalan tersebut dinamakan dengan hambatan samping yaitu sebagai aktivitas samping jalan yang sering menimbulkan konflik, dan sangat berpengaruh besar terhadap arus lalulintas. Hambatan samping seperti pejalan kaki yang menyeberang jalan, pejalan kaki yang berjalan sepanjang sisi jalan, kendaraan parkir atau berhenti di sisi jalan, kendaraan lamba, seperti becak, bendi, sepeda dan pedagang yang berjualan di pinggir jalan.

\section{DATA DAN ANALISA DATA \\ 1. Data}

Data sekunder adalah data yang diperoleh dari studi literatur dengan mempelajari penelitian - penelitian sejenis yang pernah dilakukan, teori- teori yang berkaitan dengan tingkat kecepatan kendaraan, Zona Selamat Sekolah dan teknik analisis data yang dapat menunjang penelitian. Kemudian observasi lapangan dengan melakukan kunjungan langsung kelapangan dilakukan untuk melihat kondisi dan mengukur tingkat kecepatan di lokasi ZoSS dan lokasi tidak menggunakan ZoSS. Data sekunder lainya diperoleh dari pihak terkait antara lain Dinas Pendidikan Kabupaten Pelalawan dan Dinas Perhubungan Kabupaten Pelalawan, seperti tipe jalan.

Data primer adalah data yang diperoleh langsung di lapangan yaitu waktu (detik) dan jarak ( $\mathrm{km} / \mathrm{jam})$ pada lokasi SDN 002 Kiyap Jaya Kabupataen Pelalawan, SDN 004 Lubuk Ogong Kabupaten Pelalawan, SDN 012 Pangkalan Baru Kabupaten Pelalawan, SDN 007 Simpang Beringin Kabupaten Pelalawan, SDN 001 Sei Kijang Kabupaten Pelalawan, dan TK Karya Bunda Kabupaten Pelalawan. Waktu pelaksanaan disesuaikan pada masuk dan pulang sekolah.

Kecepatan dapat diukur sebagai kecepatan titik, kecepatan perjalanan, kecepatan ruang dan kecepatan gerak (Oktaviani, 2014) :

$$
\mathrm{V}=\frac{\mathrm{d}}{\mathrm{t}}
$$

Dengan :

$$
\begin{aligned}
\mathrm{V} & =\text { Kecepatan }(\mathrm{km} / \mathrm{jam}) \\
\mathrm{d} & =\text { Jarak tempuh }(\mathrm{km}) \\
\mathrm{t} & =\text { Waktu tempuh }(\mathrm{jam})
\end{aligned}
$$

Kecepatan dikenal atas 5 macam yaitu:

a. Time mean speed (kecepatan rata-rata waktu)

Merupakan rata-rata kecepatan semua kendaraan yang lewat pada suatu titik tertentu dalam beberapa periode waktu tertentu. 


$$
\mathrm{v}_{\mathrm{t}} \quad=\frac{1}{\mathrm{n}} \sum_{\mathrm{i}=1}^{\mathrm{n}} \mathrm{v}_{\mathrm{i}}
$$

Dengan :

$\mathrm{V}_{\mathrm{t}}=$ Kecepatan rata-rata waktu (km/jam)

$\mathrm{n} \quad=$ Banyaknya data kecepatan yang diamati

$\mathrm{v}_{\mathrm{i}} \quad=$ Kecepatan tiap kendaraan yang diamati (km/jam)

b. Space mean speed (kecepatan ratarata ruang)

Merupakan rata-rata kecepatan semua kendaraan yang berada dalam suatu ruas jalan selama beberapa periode waktu tertentu. Space mean speed dihitung menggunakan rumus sebagai berikut (Oktaviani; 2014) :

$$
\mathrm{v}_{\mathrm{s}}=\frac{1}{\frac{1}{\mathrm{n}} \sum_{\mathrm{i}=1}^{\mathrm{n}} \frac{1}{\mathrm{v}_{\mathrm{i}}}}
$$

Dengan :

$$
\begin{aligned}
& \mathrm{V}_{\mathrm{s}}= \text { Kecepatan rata-rata } \\
& \mathrm{ruang}(\mathrm{km} / \mathrm{jam}) \\
& \mathrm{n}= \begin{array}{l}
\text { Banyaknya data kecepatan } \\
\text { yang diamati }
\end{array} \\
& \mathrm{v}_{\mathrm{i}}= \begin{array}{l}
\text { Kecepatan tiap kendaraan } \\
\text { yang diamati }(\mathrm{km} / \mathrm{jam})
\end{array}
\end{aligned}
$$

c. Spot Speed (kecepatan seketika)

Merupakan kecepatan yang terlihat pada speedometer.

\section{d. Running speed (kecepatan bergerak)}

Merupakan kecepatan rata-rata kendaraan selama bergerak :

$$
\begin{aligned}
& \text { Running } \\
& \text { Speed }
\end{aligned}=\frac{\text { Jarak Tempuh }}{\text { Running Time }}
$$

e. Journey speed (kecepatan perjalanan)

Adalah kecepatan rata-rata perjalanan yang dihitung dari jarak tempuh dibagi waktu tempuh.

$$
\begin{aligned}
& \text { Journey } \\
& \text { Speed }
\end{aligned}=\frac{\text { Jarak Tempuh }}{\text { JourneyTime }}
$$

\section{Analisis Data}

Dari data-data jumlah kendaraan yang melewati daerah Zoss sesuai yang didapat sesuai dengan kondisi real di lapangan. Kemudian dilakukan perhitungan menggunakan rumus kecepatan sehingga diperoleh tingkat kecepatan kendaraan yang melewati daerah ZoSS dan dianalisa berdasarkan kondisi yang ada. Berdasarkan hasil tersebut dapat diketahui tingkat kecepatan kendaraan yang melewati daerah ZoSS.

\section{HASIL DAN PEMBAHASAN}

Hasil kecepatan rata-rata pengendara pada sekolah yang memiliki fasilitas ZoSS dari hasil survey yaitu di SDN 002 Kiyap Jaya Kabupataen Pelalawan, SDN 004 Lubuk Ogong Kabupaten Pelalawan, SDN 012 Pangkalan Baru Kabupaten Pelalawan melihat kondisi jalan yang merupakan jalur lintas timur yang menghubungkan Pekanbaru dengan Kabupaten Siak dan Pelalawan dimana banyak kendaraan yang berlalu lalang baik itu kendaraan berat, kendaraan ringan dan juga sepeda motor. Waktu survey disesuaikan dengan jadwal masuk dan keluar sekolah yaitu jam masuk sekolah pada pukul 06.30 WIB s/d 07.30 WIB dan waktu pulang sekolah pukul 12.00 WIB s/d 13.00 WIB. Adapun hasil dari survey lapangan dapat dilihat pada tabel 1. 
Tabel 1. Rata-rata Kecepatan Kendaraan di Lokasi Menggunakan ZoSS

\begin{tabular}{|c|c|c|c|c|c|}
\hline \multicolumn{6}{|c|}{ Rata-rata Kecepatan Kendaraan di Lokasi Menggunakan ZoSS } \\
\hline Hari & Waktu & Nama Sekolah & n & $\mathbf{V i}$ & $\mathbf{V t}$ \\
\hline Senin & $06.30-07.30$ & \multirow{6}{*}{$\begin{array}{l}\text { SDN } 002 \\
\text { Kiyap Jaya }\end{array}$} & 287 & 9445 & 33 \\
\hline Juli 2017 & $12.00-13.00$ & & 301 & 9967 & 33 \\
\hline Selasa & $06.30-07.30$ & & 267 & 8534 & 32 \\
\hline Juli 2017 & $12.00-13.00$ & & 322 & 10233 & 32 \\
\hline \multirow{2}{*}{$\begin{array}{c}\text { Rabu } \\
\text { Juli } 2017\end{array}$} & $06.30-07.30$ & & 278 & 8977 & 32 \\
\hline & $12.00-13.00$ & & 344 & 11233 & 32 \\
\hline \multirow{2}{*}{$\begin{array}{c}\text { Senin } \\
\text { Juli } 2017\end{array}$} & $06.30-07.30$ & \multirow{6}{*}{$\begin{array}{c}\text { SDN } 004 \\
\text { Lubuk Ogong }\end{array}$} & 305 & 10341 & 34 \\
\hline & $12.00-13.00$ & & 311 & 10023 & 32 \\
\hline \multirow{2}{*}{$\begin{array}{c}\text { Selasa } \\
\text { Juli } 2017\end{array}$} & $06.30-07.30$ & & 299 & 9034 & 30 \\
\hline & $12.00-13.00$ & & 345 & 11339 & 33 \\
\hline \multirow{2}{*}{$\begin{array}{c}\text { Rabu } \\
\text { Juli } 2017 \\
\end{array}$} & $06.30-07.30$ & & 312 & 10223 & 33 \\
\hline & $12.00-13.00$ & & 399 & 13445 & 34 \\
\hline \multirow{2}{*}{$\begin{array}{c}\text { Senin } \\
\text { Juli } 2017\end{array}$} & $06.30-07.30$ & \multirow{6}{*}{$\begin{array}{c}\text { SDN 012 } \\
\text { Pangkalan Baru }\end{array}$} & 312 & 10123 & 32 \\
\hline & $12.00-13.00$ & & 275 & 8908 & 32 \\
\hline \multirow{2}{*}{$\begin{array}{c}\text { Selasa } \\
\text { Juli } 2017\end{array}$} & $06.30-07.30$ & & 203 & 7988 & 39 \\
\hline & $12.00-13.00$ & & 342 & 11210 & 33 \\
\hline \multirow{2}{*}{$\begin{array}{c}\text { Rabu } \\
\text { Juli } 2017\end{array}$} & $06.30-07.30$ & & 201 & 7998 & 40 \\
\hline & $12.00-13.00$ & & 185 & 7880 & 43 \\
\hline & & Rata-rata & & & 34 \\
\hline
\end{tabular}

Dari hasi data yang kita peroleh pada sekolah SDN 002 Kiyap Jaya Kabupaten Pelalawan, SDN 004 Lubuk Ogong Kabupaten Pelalawan, SDN 012 Pangkalan Baru Kabupaten Pelalawan yang telah memiliki daerah ZoSS seperti ditunjukkan pada tabel 1, terlihat bahwa kecepatan kendaraan yang melewati daerah ZoSS berkisar antara $32-40 \mathrm{~km} / \mathrm{jam}$ dengan rata-rata 34 $\mathrm{km} / \mathrm{jam}$.

Sedangkan hasil kecepatan ratarata pengendara pada sekolah yang tidak memiliki fasilitas ZoSS dari hasil survey yaitu SDN 007 Simpang Beringin Kabupaten Pelalawan, SDN 001 Sei Kijang Kabupaten Pelalawan, dan TK Karya Bunda Kabupaten Pelalawan melihat kondisi jalan yang merupakan jalur lintas timur yang menghubungkan Pekanbaru dengan Kabupaten Siak dan Pelalawan, dimana banyak kendaraan yang berlalu lalang baik itu kendaraan berat, kendaraan ringan dan juga sepeda motor. Waktu survey disesuaikan dengan jadwal masuk dan keluar sekolah yaitu jam masuk sekolah pada pukul 06.30 WIB s/d 07.30 WIB dan waktu pulang sekolah pukul 12.00 WIB s/d 13.00 WIB. Adapun hasil dari survey lapangan dapat dilihat pada tabel 2 .

Dari hasil data yang kita peroleh pada sekolah SDN 007 Simpang Beringin Kabupaten Pelalawan, SDN 001 Sei Kijang Kabupaten Pelalawan, dan TK Karya Bunda Kabupaten Pelalawan yang telah memiliki daerah ZoSS seperti ditunjukkan pada tabel 2, terlihat bahwa kecepatan kendaraan yang melewati daerah ZoSS berkisar antara 33 - $42 \mathrm{~km} / \mathrm{jam}$ dengan rata-rata $36 \mathrm{~km} / \mathrm{jam}$. 
Tabel 2. Rata-rata Kecepatan Kendaraan di Lokasi Tidak Menggunakan ZoSS

\begin{tabular}{|c|c|c|c|c|c|}
\hline \multicolumn{6}{|c|}{ Rata-rata Kecepatan Kendaraan di Lokasi Tidak Menggunakan ZoSS } \\
\hline Hari & Waktu & Nama Sekolah & $\mathbf{N}$ & $\mathbf{V i}$ & $\mathbf{V t}$ \\
\hline Senin & $06.30-07.30$ & \multirow{6}{*}{$\begin{array}{c}\text { SDN } 007 \\
\text { Simpang Beringin }\end{array}$} & 344 & 12449 & 36 \\
\hline Juli 2017 & $12.00-13.00$ & & 299 & 10335 & 35 \\
\hline Selasa & $06.30-07.30$ & & 313 & 10455 & 33 \\
\hline Juli 2017 & $12.00-13.00$ & & 322 & 11224 & 35 \\
\hline \multirow{2}{*}{$\begin{array}{c}\text { Rabu } \\
\text { Juli } 2017\end{array}$} & $06.30-07.30$ & & 278 & 10221 & 37 \\
\hline & $12.00-13.00$ & & 301 & 9934 & 33 \\
\hline \multirow{2}{*}{$\begin{array}{l}\text { Senin } \\
\text { Juli } 2017\end{array}$} & $06.30-07.30$ & \multirow{6}{*}{$\begin{array}{l}\text { SDN } 001 \\
\text { Sei Kijang }\end{array}$} & 305 & 10123 & 33 \\
\hline & $12.00-13.00$ & & 311 & 10412 & 33 \\
\hline Selasa & $06.30-07.30$ & & 299 & 10433 & 35 \\
\hline Juli 2017 & $12.00-13.00$ & & 345 & 12544 & 36 \\
\hline \multirow{2}{*}{$\begin{array}{c}\text { Rabu } \\
\text { Juli } 2017\end{array}$} & $06.30-07.30$ & & 312 & 10355 & 33 \\
\hline & $12.00-13.00$ & & 399 & 13223 & 33 \\
\hline \multirow{2}{*}{$\begin{array}{c}\text { Senin } \\
\text { Juli } 2017\end{array}$} & $06.30-07.30$ & \multirow{6}{*}{$\begin{array}{c}\text { TK } \\
\text { Karya Bunda }\end{array}$} & 312 & 11231 & 36 \\
\hline & $12.00-13.00$ & & 275 & 10112 & 37 \\
\hline Selasa & $06.30-07.30$ & & 211 & 8011 & 38 \\
\hline Juli 2017 & $12.00-13.00$ & & 342 & 12655 & 37 \\
\hline \multirow{3}{*}{$\begin{array}{c}\text { Rabu } \\
\text { Juli } 2017\end{array}$} & $06.30-07.30$ & & 201 & 7823 & 39 \\
\hline & $12.00-13.00$ & & 185 & 7834 & 42 \\
\hline & & Rata-rata & & & 36 \\
\hline
\end{tabular}

\section{E. KESIMPULAN}

Dari hasil survey yang telah dilakukan terlihat bahwa:

1. Kecepatan rata-rata kendaraan yang melewati ZoSS melebihi batas kecepatan standar yang diizinkan (30 km/jam untuk jalan luar kota) yaitu $35 \mathrm{~km} / \mathrm{jam}$.

2. Kecepatan rata-rata kendaraan yang melewati area sekolah yang tidak memiliki area ZoSS melebihi batas kecepatan standar yang diizinkan (30 km/jam untuk jalan luar kota) yaitu 37 km/jam.

\section{DAFTAR PUSTAKA}

Data Riau.com, 2014, Jalan HR Soebrantas, Lintasan Maut di Pekanbaru, Retrieved : April 13, 2016, From :

http://datariau.com/read-13-8292014-10-24-jalan-hr-soebrantaslintasan-maut-di-pekanbaru.html,
Kurniati T., dkk., 2010, Evaluasi Penerapan Zona Selamat Sekolah di Kota Padang, Jurnal Rekayasa Sipil, Volume 6 Nomor $2: 7-10$.

Oktaviani, 2014, Teknik Lalu Lintas, Teknik Sipil Fakultas Teknik Universitas Negeri Padang, Padang.

Kementerian Perhubungan, 2014, Peraturan Menteri Perhubungan Republik Indonesia Nomor PM 13 Tahun 2014 Tentang Rambu Lalu Lintas, Jakarta.

Kementerian Perhubungan, 2014, Peraturan Menteri Perhubungan Republik Indonesia Nomor PM 34 Tahun 2014 Tentang Marka Jalan, Jakarta.

Putri L.D., Soehardi F., Saleh A., 2017, Tinjauan Kecepatan Kendaraan Pada Wilayah Zona Selamat Sekolah di Kota Pekanbaru, http://doi.org/10.17605/OSF.IO/D 5QW6. 
Sari N.M., 2015, Tinjauan Kecepatan Kendaraan pada Wilayah Zona Selamat Sekolah (ZoSS) di Kota Padang, Prosiding Annual Civil Engineering Seminar, ISBN : 978979-792-636-6, Universitas Riau, Pekanbaru.

Sari N.M., 2015, Tinjauan Kecepatan Kendaraan pada Wilayah Zona Selamat Sekolah (ZoSS) di Kota Padang, Retrieved : February 07, 2016, From :

ejournal.unri.ac.id/ACES/article/d ownload/2994/2926.
Tamin O.Z., 2008, Perencanaan, Pemodelan dan Rekayasa Transportasi, Institut Teknologi Bandung, Bandung.

Wahyuni S., 2012, Analisis Efektifitas Zona Selamat Sekolah (ZoSS) di Sekolah Dasar Kota Pekanbaru, Retrieved : April 03, 2016, From: http://repository.unri.ac.id/xmlui/b itstream/handle/123456789/2050/ SRI\%20WAHYUNI\%20\%20(NI M\%200707131855).pdf?sequence $=1$. 